\title{
EVALUATION OF POSTOPERATIVE PAIN IN MANDIBULAR FIRST MOLAR AFTER INSTRUMENTATION WITH DIFFERENT FILES MOTIONS
}

\author{
Ali O Bazuhair*, Taher M Islam **, Moataz B Alkhawas ***
}

\begin{abstract}
Objective: The present study was performed to evaluate of postoperative pain in mandibular first molar after instrumentation with different files metallurgy with different motions with or without activation of irrigant.

Methods: 60 male that need root canal treatment for their mandibular first molar were dividing to six groups. Group A1B1: Instrumentation using XP endo Shaper with activation using XP endo finisher. Group A1B2: Instrumentation using XP endo Shaper with traditional side vented needle irrigation. Group A2B1: Instrumentation using 2Shape files with activation using XP endo finisher. Group A2B2: Instrumentation using 2Shape files with traditional side vented needle irrigation. Group A3B1: Instrumentation using Reciproc Blue with activation using XP endo finisher. Group A3B2: Instrumentation using Reciproc Blue with traditional side vented needle irrigation. Then evaluate the postoperative pain at 12,48 and 72 hours.
\end{abstract}

Results: Results of the study showed that the highest mean pain score value was recorded with Reciproc blue at all intervals while activation of the irrigating solution, the results showed dramatically decrease in the postoperative pain level when XP finisher was used following root canal instrumentation using Recioproc blue.

Conclusions: Reciproc blue reciprocating file induces postoperative pain than XP endo shaper and 2Shape continuous rotation systems.

\section{INTRODUCTION}

Postoperative pain is unpleasant sensation of the patient that may occur shortly after root canal treatment. It may last for a few hours or days. Postoperative pain after nonsurgical root canal has been reported to range from approximately $3 \%$ to more than $50 \%{ }^{(1)}$. Unfortunately, the patient may develop postoperative pain as a result of microbial, mechanical or chemical injury to the periapical area during root canal treatment. Regarding microbial injury, forcing the debris that is loaded with microorganism and their necrotic byproduct beyond the apex may lead to serious complication with resultant postoperative pain ${ }^{(2)}$. On the other hand, mechanical injury to the periapical area as result of over instrumentation when using traditional instrument may irritate the periapical tissue with development of postoperative pain very shortly following root canal treatment. Also, extrusion of the irrigating solutions or intracanal medicaments may induce inflammatory response to the periapical tissues with resultant postoperative pain ${ }^{(3)}$. The key role to reduce postoperative pain after root canal treatment is to avoid debris, irrigants and medicaments extrusion beyond the apex and to avoid over instrumentation of the periapical tissues. Unfortunately, some sort of postoperative pain is still evident after root canal treatment that may need pain killer.

On the other hand, activation of the irrigating solution may reduce the microbial biofilm inside the root canal system that indirectly may

* Dentist at Private Clinic.

** Professor, Department of Endodontics, Faculty of Dental Medicine, Boys, Cairo Al-Azhar University.

*** Associate Professor, Department of Endodontics, Faculty of Dental Medicine, Boys, Cairo Al-Azhar University. 
reduce postoperative pain $^{(4)}$. Furthermore, the instrumentation motions either continuous rotation or reciprocation may be one of the predisposing factors that induce postoperative pain ${ }^{(5)}$.

\section{PATIENT AND METHODS}

Out of 90 patients, 60 male healthy patients aged between 18 to 35 years old that need root canal treatment for their mandibular first molar were selected from the outpatient endodontic clinic at the Faculty of Dental Medicine, Al-Azhar University, Boys, Cairo to be included in this Randomized clinical study. History from all patients including, past and present medical and dental histories followed by chief complain collection were taken. Extra oral examination was done to detect any extra oral swelling and/or presence or absence of sinus tract. This was followed by intraoral examination including soft and hard tissue visualization, palpation of the periapical area, vertical and horizontal percussion, mobility test, probing test and vitality test of the selected tooth. Radiographic examination using 2 periapical radiographs from different angulations was done to confirm presence of 4 canals independent in each molar and to confirm absence of apical periodontitis.

\section{Preoperative pain assessment:}

Preoperative pain assessment of the patients selected teeth with acute pulpitis was done by the operator according to a scale modified from the modified verbal Descriptor scale (VDS) described by Mathias Haefli ${ }^{(6)}$. Patients with a score level(4-6) were included in the study

\section{Ethical considerations:}

The research objectives were explained to the patients in details and an informed consent was signed by all patients before starting treatment.

\section{Grouping of the patients:}

Prior to single visit root canal treatment of the patients' teeth, grouping was done as follows:
Group A1B1: Instrumentation using XP endo Shaper with activation using XP endo finisher. Group A1B2: Instrumentation using XP endo Shaper with traditional side vented needle irrigation. Group A2B1: Instrumentation using 2Shape files with activation using XP endo finisher. Group A2B2: Instrumentation using 2Shape files with traditional side vented needle irrigation. Group A3B1: Instrumentation using Reciproc Blue with activation using XP endo finisher. Group A3B2: Instrumentation using Reciproc Blue with traditional side vented needle irrigation. Anaesthetization of the patient and isolation of the field was done. Cleaning and shaping and irrigation methods done as manufacture instructions. Followed by obturation of the teeth by cold lateral condensation.

\section{Postoperative pain assessments:}

At the end of the visit and prior to patient dismiss the operator motivated the patient how to use modified VDS by describing each level of pain intensity within the scale. Patients were given a copy of the Arabic modified VDS and asked to mark the level of pain intensity felt postoperatively after 12, 48 and hours. Postoperative assessment was collected by from the patient after 72 hours when final coronal restoration was done. The patients were instructed to take $600 \mathrm{mg}$ ibuprofen on demand.

\section{RESULT}

Evaluation of postoperative pain among all groups in each time interval:

\section{Preoperative:}

The results showed that the highest mean pain score value was recorded with XP shaper/ XP finisher group $(5.40 \pm 0.84)$ followed by XP shaper (5.20 \pm 0.90$), \quad 2$ shape /XP finisher (5.0 \pm 0.99$)$, Reciproc blue / XP finisher (5.10 \pm 0.88$)$, 2shape $(4.90 \pm 0.99)$ groups while the lowest mean score pain value was recorded with Reciproc blue $(4.0 \pm 0.99)$ group with no significant difference among all groups $\mathrm{P}$ value $=0.819$. 


\section{Postoperative after 12 hours:}

The result showed that the highest mean pain score value was recorded with Reciproc blue (7.10 \pm 0.88$)$ that showed statistically significant difference with each of Reciproc blue / Xp finisher (5.80 \pm 0.79$)$, 2shape / XP finisher $(5.10+1.20)$, XP shaper $(4.80+1.23)$, XP shaper / XP finisher (4.70 \pm 0.67$)$ groups, while the lowest mean pain score value was recorded with 2shape (4.20土1.40) group that showed statistically significant difference with other groups. P value $<0.001$.

\section{Postoperative after 48 hours:}

The result showed that the highest mean pain score value was recorded with Reciproc blue $(6.70 \pm 1.06)$ group that showed statistically significant difference with each of Reciproc blue/Xp

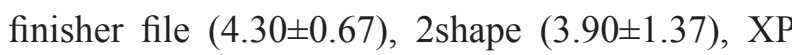
shaper / XP finisher (3.80 \pm 0.92$)$, 2shape / XP finisher $(3.80 \pm 0.63)$ groups, while the lowest mean pain score value was recorded with XP shaper $(3.60+0.70)$ group that showed statistically significant difference with other groups. $\mathrm{P}$ value $=0.001$.

\section{Postoperative after 72 hours:}

The result showed that the highest mean pain score value was recorded with Reciproc blue /XP finisher $(3.00 \pm 0.82)$ group that showed statistically significant difference with each of Reciproc blue

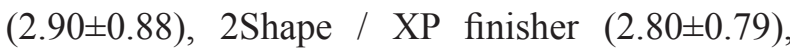
XP shaper (2.30 \pm 1.06$)$, XP shaper / XP finisher $(2.30 \pm 0.48)$ group, while the lowest mean pain score value was recorded with 2 shape $(1.50 \pm 1.58)$ group that showed statistically significant difference with other groups. $\mathrm{P}$ value $=0.024$.

TABLE (1). The mean, standard deviation (SD) values of pain score of Different groups in different time periods.

\begin{tabular}{|c|c|c|c|c|c|c|c|c|}
\hline \multirow{3}{*}{ Variables } & \multicolumn{8}{|c|}{ Pain } \\
\hline & \multicolumn{2}{|c|}{ Pre } & \multicolumn{2}{|c|}{ After 12 hours } & \multicolumn{2}{|c|}{ After 48 hours } & \multicolumn{2}{|c|}{ After 72 hours } \\
\hline & Mean & SD & Mean & SD & Mean & SD & Mean & SD \\
\hline $\mathbf{X P}$ & $5.20^{\mathrm{a}}$ & 0.92 & $4.80^{\mathrm{bc}}$ & 1.23 & $3.60^{\mathrm{c}}$ & 0.70 & $2.30^{\mathrm{abc}}$ & 1.06 \\
\hline XP with XP finisher & $5.40^{\mathrm{a}}$ & 0.84 & $4.70^{\mathrm{c}}$ & 0.67 & $3.80^{\mathrm{bc}}$ & 0.92 & $2.30^{\mathrm{bc}}$ & 0.48 \\
\hline 2Shape & $4.90^{\mathrm{a}}$ & 0.99 & $4.20^{c}$ & 1.40 & $3.90^{b c}$ & 1.37 & $1.50^{\mathrm{c}}$ & 1.58 \\
\hline 2Shape with XP finisher & $5.00^{\mathrm{a}}$ & 0.94 & $5.10^{\mathrm{bc}}$ & 1.20 & $3.80^{\mathrm{bc}}$ & 0.63 & $2.80^{\mathrm{ab}}$ & 0.79 \\
\hline Reciproc & $4.90^{\mathrm{a}}$ & 0.99 & $7.10^{\mathrm{a}}$ & 0.88 & $6.70^{\mathrm{a}}$ & 1.06 & $2.90^{\mathrm{ab}}$ & 0.88 \\
\hline Reciproc with XP finisher & $5.10^{\mathrm{a}}$ & 0.88 & $5.80^{\mathrm{b}}$ & 0.79 & $4.30^{\mathrm{b}}$ & 0.67 & $3.00^{\mathrm{a}}$ & 0.82 \\
\hline p-value & \multicolumn{2}{|c|}{$0.819 \mathrm{~ns}$} & \multicolumn{2}{|c|}{$<0.001 *$} & \multicolumn{2}{|c|}{$<0.001 \%$} & \multicolumn{2}{|c|}{$0.024 *$} \\
\hline
\end{tabular}

\section{DISCUSSION}

This study evaluated the effect of using 3 different instrumentation systems (XP Shaper, 2Shap and Reciproc blue), with/without irrigant activation using XP endo finisher on the postoperative pain after single visit treatment of teeth with irreversible pulpitis.
Male patients aged 18-35 years were selected in the study to decrease the effect of hormonal changes that are usually associated with female patients while keeping similar patient response within the selected age range ${ }^{(7)}$.

Patients who had teeth with irreversible pulpitis were included to eliminate the effect of the periapical status of the affected teeth 
Postoperative pain has been more frequently reported in the mandibular posterior teeth $(42 \%)$ in comparison with maxillary posterior teeth $(26 \%)$ due to thick cortical mandibular plate that allows for the accumulation of exudates and increasing the intra-periapical pressure that produces pain ${ }^{\left({ }^{(8)}\right.}$.

Creation of a glide path and canal patency prior to and during instrumentation of the root canals respectively were done to minimize extrusion of debris outside the apical foramen with decreasing the risk of postoperative pain ${ }^{(9)}$.

Sodium hypochlorite irrigating solution was used due to it has broad antibacterial activity and organic matter dissolution ability. While using EDTA 17\% irrigating solution was due to its ability in removing the inorganic content of the smear layer which accumulates as a result of the mechanical cleaning and shaping ${ }^{(10)}$.

Assessment of pain intensity was carried preoperatively and postoperatively after 12,48 , and 72 hours. These intervals were chosen as $12-\mathrm{h}$ was after instrumentation enough to allow the anesthetic solution effect to completely disappear. Finally, 48 hours and 72 hours intervals where chosen because it usually represents the period of the maximum peak of pain ${ }^{(11)}$.

In the present study, the highest pain levels were recorded with Reciproc blue than XP shaper and 2Shape groups at different time intervals (12, 48 and 72 hours postoperative). This finding is in agreement with Oubaid, Mehdi, ${ }^{(12)}$ and Nekoofar et $\mathrm{al}^{(13)}$ who found that postoperative pain level was significantly lower in patient treated with the rotary systems than those treated with reciprocating system. Alternatively, the present study was in contrast with the results found by Kherlakian et al ${ }^{(14)}$ and Revals et al ${ }^{(15)}$. They reported that no significant difference in postoperative pain levels between rotary and reciprocating motions.
The significant difference in the present study may be attributed to the extrusion of debris, as reciprocating motion is responsible for extruding higher amount of debris than rotary motion, due to reciprocating motion is formed by a wider cutting angle and smaller releasing angle, while rotating in the releasing angle direction, the flutes did not remove debris rather than push it apically ${ }^{(16)}$.

On the other hand, XP Shaper and 2Shape groups showed lower postoperative pain level than Reciproc blue group which may be due to their continuous rotation motions with less debris extrusion beside the 2Shape has asymmetrical cross section with 2 main cutting edge and 1 secondary edge that augments removal of debris from inside root canal while XP Shaper has a snake movement while expanding and contracting during relatively long strokes, may improve touch on the canal walls ${ }^{(17)}$.

Additionally, 2Shape group showed lower postoperative pain than XP shaper group as the 2Shape is a multi-file ${ }^{(18)}$ system with less apical diameter $(0.25 \mathrm{~mm})$ while Xp shaper single file system with larger apical diameter $(0.30 \mathrm{~mm})$ Also, the difference may be attributed to the difference in metallurgy between both rotary systems as the friction to the canal wall make the Max wire alloy of XP endo shaper more expandable by temperature raising inside the root canal leading to pushing more debris outside the apex in compare with $\mathrm{T}$ wire alloy of 2Shape rotary system that has a standard apical diameter and tapper.

Regarding activation of the irrigating solution, the results showed dramatically decrease in postoperative pain level when XP finisher was used following root canal instrumentation using Reciproc blue file on the other hand, XP finisher did not significantly decrease the postoperative pain levels following root canal instrumentation using XP shaper and 2shape groups. This may be attributed to greater canal taper when instrumentation with Reciproc blue (0.08 taper) in compared with that 
XP shaper (0.04 taper) and 2shape (0.06 taper) rotary systems. The greater canal taper allows for better debris removal especially from the apical third of the root canals that were instrumented with Reciproc blue reciprocating file. These results are agreement with Leoni et al. ${ }^{(19)}$ who found that XP-endo Finisher instrument were associated with significantly lower levels of accumulated hard tissue debris( AHTD) compared with conventional irrigation and the modified SAF system protocol and disagreement with Kfir A et al ${ }^{(20)}$ who found that Rotary file followed by XP-endo Finisher file extruded significantly more debris than a fullsequence SAF system. The difference between them may attributed to difference in methodology. However the results of the present study rejected the null hypothesis that there was no significant difference among all groups.

\section{CONCLUSION}

All of the tested rotary and reciprocating instruments induce postoperative pain with variable levels. Reciproc blue reciprocating file induces postoperative pain than XP endo shaper and 2Shape continuous rotation systems. Activation of the irrigating solution using XP endo Finisher file is effective in reducing postoperative pain when using Reciproc blue reciprocating system.

\section{REFERENCES}

1. Polycarpou N, Ng Y, Canavan D, Moles R, Gulabivala K. Prevalence of persistant pain after endodontic treatment and factors affecting its occurrence in cases with complete radiographic healing. Int Endod J 2005; 38:169-378.

2. Su Y, Wang C, Ye L. Healing rate and post-obturation pain of single-versus multiple-visit endodontic treatment for infected root canals: A systemic review. J Endod 2011; $37: 125-32$.

3. Arias A, Azabal M, Hidalgo J, De la macorra J. Relation between postendodontic pain, tooth diagnostic factors and apical patency. J Endod 2009; 35:189-92.

4. Peters B, van Winkelhoff J, Buijs J, Wesselink P: Effects of instrumentation, irrigation and dressing with calcium hydroxide on infection in pulpless teeth with periapical bone lesions. Int Endod J.2002; 35:13-21.

5. Garcia-Font M, Durán-Sindreu F, Morelló S, Irazusta $S$, Abella F, Roig $M$ et al Postoperative pain after endodontic retreatment using rotary or reciprocating instruments: A Randomized Clinical Trial. J Endod. 2017; 43:1084-88

6. Haefeli M, Elfering A. Pain assessment. Eur Spine J 2006; $15: 17-24$.

7. AriasoA, deolaoMacorraoC, HidalgooJ, AzabaloM.. Predictive models of pain following root canal treatment: a prospective clinical study. Int EndodJ.2013; 46:784-93.

8. Menke R, Jackson R, Bagby D, Tracy S. The effectiveness of prophylactic etodolac on postendodontic pain $\mathrm{J}$ Endod. 2000; 26:712-5.

9. Ruddle J, Machtou P, West D. Endodontic canal preparation: new innovations in glide path management and shaping canals. Dent today. 2014; 33:118-23

10. Siqueira F, Rôças N , Favieri A, Lima C. Chemomechanical reduction of the bacterial population in the root canal after instrumentation and irrigation with $1 \%, 2.5 \%$, and 5.25\% sodium hypochlorite. J Endod.2000; 26:331-4.

11. Topçuoğlu G, Topçuoğlu S, Delikan E, Aydınbelge M, Dogan S, Postoperative Pain After Root Canal Preparation with Hand and Rotary Files in Primary Molar Teeth. Pediatr Dent. 2017; 39:192-196.

12. Mehdi A, Oubaid H. Incidence and severity of pain following the usage of three different root canal instrumentation systems. Journal of Oral and Dental Research. 2016; $3: 20-7$.

13. Nekoofar H, Sheykhrezae S, Meraji N, Jamee A, Shirvani A, Jamee J,Comparison ofothe effect of root canal preparation byousing WavekOne and ProTaper on postoperative pain: a randomized clinical trial. J Endod. 2015; 41:575-8.

14. Kherlakian D, Cunha S, Ehrhardt C, Zuolo L, Kishen A, da Silveira Bueno E. Comparison of the incidence of postoperative pain after using 2 reciprocating systems and a continuous rotary system: A prospective randomized clinical trial. J Endod. 2016; 42:171-76.

15. Relvas B, Bastos M, Marques A, Garrido D, Sponchiado $\mathrm{C}$ Jr. Assessment of postoperative pain after reciprocating or rotary NiTi instrumentation of root canals: a randomized, controlled clinical trial. Clin Oral Investig. 2016 ;20: 1987-93. 
16. Bürklein S, Schäfer E. Apically Extruded Debris with Reciprocating Single-File and Full-sequence Rotary Instrumentation Systems. J Endod. 2012; 38:850-52.

17. Alves F, Paiva L, Marceliano-Alves F, Cabreira J, Lima C, Siqueira F Jr, Bacteria and Hard Tissue Debris Extrusion and Intracanal Bacterial Reduction Promoted by XP-endo Shaper and Reciproc Instruments. JEndod. 2018; 44:1173-78.

18. Saberi E, Zahedani SS, Ebrahimipour S Apical extrusion of intra canal bacteria with single file and Multifile rotary instrument system. J Int Soc Prev Community Dent 2017:7:292-96.
19. Leoni B, Versiani A, Silva-Sousa T, Bruniera F, Pécora D, Sousa-NetofMD.Ex vivo evaluation of four final irrigation protocols onothe removal of

20. hard- tissue debris from the mesial root canal system of mandibular first molars. Int Endod J. 2017; 50: 398-406.

21. Kfir A, Moza-Levi R, Herteanu M, Weissman A, Wigler $\mathrm{R}$. Apical extrusion of debris during the preparation of oval root canals acompartive study between a full-sequence SAF system and a rotary file system supplemented by XPendo finisher file .Clin Oral Investig. 2018: 22:707-13. 